\title{
Research
}

\section{The Quality and Outcomes Framework and self-management dialogue in primary care consultations:}

\section{a qualitative study}

\begin{abstract}
\section{Background}

Two key elements to improve the quality of care for people with long-term conditions in primary care are improved clinical information systems to support delivery of evidence-based care, and enhanced self-management support. Although both elements are viewed as necessary, their interaction is not well understood.
\end{abstract}

\section{Aim}

To explore the use of computer-based 'disease management' templates and their relevance to self-management dialogue within clinical encounters.

\section{Design and setting}

Qualitative study of general practices located in three primary care trusts in the north of England.

\section{Method}

A qualitative mixed methods study was conducted that included comparative analysis of (1) observations of general practice consultations ( $n=86)$; and (2) interviews with health professionals in general practice $(n=17)$.

\section{Results}

The analysis suggested that use of the computer templates reinforced a checklist approach to consultations, which included professionals working through several selfmanagement topics framed as discrete behaviours. As a consequence, conversation tended to become focused on the maintenance of the professional-patient relationship at the expense of expansion in self-management dialogue. The computer templates also shaped how patient-initiated self-management dialogue was managed when it arose, with a shift towards discussion around medical agendas.

\section{Conclusion}

In order to enhance the management of longterm conditions in primary care, the design and implementation of clinical information systems to improve evidence-based care need to take into account their potential impact on supporting self-management.

\section{Keywords}

consultation; chronic disease; doctor-patient relations; primary care; self-management.

\section{INTRODUCTION}

Worldwide, reorganising health services is viewed as essential to improve care for people with long-term conditions., ${ }^{1,2}$ To achieve 'productive interactions', the Chronic Care Model and the NHS and Social Care Long Term Conditions Model highlight key system components that need to be addressed. ${ }^{1-3}$ These components comprise delivery system design, decision support, clinical information systems, and selfmanagement support.1,2

In the UK, the Quality and Outcomes Framework (QOF) remunerates professionals for providing evidence-based care in line with clinical quality indicators. Clinical information systems, consisting of computer templates, have been developed to help professionals deliver such care.

Supporting self-management refers to help in 'managing or minimising the way conditions limit individuals' lives as well as what they can do to feel happy and fulfilled to make the most of their lives despite their condition'.$^{5-7}$ Recognising that primary care is one of many settings for such support GPs and practice nurses are viewed as an important resource for supporting patients to monitor their condition; deal with medication; improve lifestyle; and improve access to community support. 2,8,9

Current evidence suggests that interventions that address at least one component of the Chronic Care Model, and in particular self-management support and

T Blakeman, PhD, MRCGP, NIHR clinical lecturer in primary care; $\mathbf{D}$ Reeves, $\mathrm{PhD}$, senior research fellow; A Rogers, PhD, professor of the sociology of health care, School of Community Based Medicine, Health Sciences, Primary Care Research Group. C Chew-Graham, MD, FRCGP, professor of primary care; $\mathbf{P}$ Bower, PhD, reader, Health Services Research NIHR School for Primary Care Research, The University of Manchester, Manchester.

\section{Address for correspondence}

Tom Blakeman, School of Community Based Medicine, Health Sciences, Primary Care delivery system design, lead to improved process and outcomes of care. ${ }^{10,11}$ However, less is known about how the key components interact. ${ }^{10,11}$ In the UK, the QOF has been shown to improve the quality of clinical care. ${ }^{12,13}$ Nevertheless, there remain concerns that it promotes a mechanistic approach' to long-term conditions, with accounts suggesting that it has contributed to a shift away from person-focused care. 14,15

The study aimed to explore selfmanagement support in primary care consultations. Previous articles have highlighted the tensions that exist in supporting self-management in primary care. ${ }^{16,17}$ Building on these findings, this paper focuses on the use of clinical information systems (in the form of computer-based 'disease management' templates) and their relevance to selfmanagement dialogue within clinical encounters.

\section{METHOD}

\section{Study design}

A qualitative mixed methods study was conducted that focused on understanding typical management of long-term conditions in primary care. ${ }^{17}$ It was assumed that comparative analysis of interview and observational data improved understanding of the phenomenon. ${ }^{18}$ The study was hypothesis-generating and designed to explore dialogue around self-management topics in routine clinical practice.

Research Group, The University of Manchester Williamson Building, Oxford Road, Manchester M13 9PL.

E-mail: tom.blakemandamanchester.ac.uk Submitted: 12 November 2010; Editor's response: 13 December 2010; final acceptance: 14 February 2011

\section{(CBritish Journal of General Practice}

This is the full-length article (published online 26 Sep 2011) of an abridged version published in print. Cite this article as: Br J Gen Pract 2011; DOI: 10.3399/bjgp11X601389. 


\section{How this fits in}

Key elements to improve care for people with long-term conditions have been identified and include clinical information systems and self-management support. However, less is known about how these elements interact in practice. Through comparative analysis of both observational and interview data, the research suggests that current use of computer-based disease-management templates reinforces difficulties in supporting self-management in UK primary care consultations. The design and implementation of clinical information systems need to ensure that self-management dialogue can occur in a manner that does not threaten the professional-patient relationship.

The study took the perspective that a meaningful reality was being constructed through the researchers' interaction with the participants and the data. ${ }^{19}$ Throughout the research, analytic methods were therefore chosen that sought to reduce the likelihood of superimposing 'preconceived notions' of general practice consultations onto the data. ${ }^{20}$ In particular, as well as treating interview accounts as actively constructed narratives', organisational structures such as computer templates were not viewed merely as external determinants of behaviour.20-24 Rather, through exploration of statements and taken-for-granted actions, the analysis focused on how templates became relevant through interaction. ${ }^{20,23-26}$

Between 2006 and 2008, data were collected in general practices based in three primary care trusts in the north of England. This included generation of three sources of data:

- recordings of general practice consultations;

- face-to-face interviews with health professionals; and

- face-to-face interviews with patients living with a long-term condition.

\section{Sampling}

Health professionals and patients were purposively sampled to explore a variety of experiences. This included maximal variation sampling of GPs according to geographical location; age; sex; practice size; contractual status; and whether the practice conducted disease-management clinics in addition to routine surgeries.
Practice nurses and other professionals working in the same practices were subsequently invited to participate. This was followed by recruiting patients attending for appointments within either routine surgeries or disease-management clinics.

\section{Data collection}

The research focused on the management of long-term conditions. As reasons for attendance were not known prior to consultation, all adults attending recorded surgeries were invited to have their consultation digitally video-recorded. In total, 96 out of 121 patients (79\%) agreed to participate. Of these, 86 consultations related to patients living with a long-term condition.

Semi-structured interviews were conducted with participating health professionals 1 week after surgery recordings. The final sample comprised 11 GPs, four practice nurses; one nurse practitioner; and one assistant health practitioner. The interviews lasted approximately 1 hour (range 42-113 minutes) and focused on participants' roles in the management of patients with long-term conditions. In order to stimulate accounts, the professionals were asked to comment on a sample of recorded consultations. ${ }^{17,18,27}$

Semi-structured interviews were also carried out with 12 patients with long-term conditions. These were primarily conducted with patients whose consultation had been discussed during professional interviews. Interviews (median length 50 minutes, range 19-83 minutes) explored individuals' experiences of living with a long-term condition, including the role of consultations with health professionals.

\section{Data analysis}

Constant comparative methods were employed in order to enhance conceptual understanding. This entailed making comparisons within and across a variety of participant perspectives as well as a range of consultation recordings. ${ }^{20,24}$ Generating a research archive that comprised both interview and observational data enabled engagement in an interplay between two analytic foci: an analysis of discourses that participants entered into; and an analysis of discursive practice surrounding management of long-term conditions in primary care. 24,25

A key finding that emerged during initial analysis of patient and professional accounts concerned a tension in addressing self-management topics without upsetting 
the professional-patient relationship. ${ }^{17}$ Maintaining social relations is a key principle underpinning conversation analysis. ${ }^{28}$ Therefore, methods used in the analysis of conversation were employed to understand attempts to achieve this in primary care consultations. ${ }^{24}$

The level of detail in transcription of conversation can be a simple description of a recorded event; a verbatim transcript; or a detailed 'technical' transcription using notation systems. ${ }^{24}$ Determining the level of detail in transcription of the consultation recordings was informed by the research questions being posed, pragmatic issues, and the necessity of ensuring that the process of transcription contained sufficient detail to challenge pre-existing knowledge. Recognising that the process of transcription was itself an interpretive activity, digital recordings of consultations were transcribed using Poland's framework. 24,29

Analysis of conversation entailed exploring turn taking between participants; the organisation of sequences of talk; the overall structure of the consultation; the choice of words used by participants; and non-verbal interactions between participants and objects in the room including computers. ${ }^{24}$

Researchers coded both what and how self-management topics were introduced and managed during consultations. This focused on how participants discussed dealing with medicines; lifestyle behaviours; monitoring of a condition; psychosocial issues; and links to other support services.?

In summary, through constant comparison of interview and observational data, an understanding was constructed of how patients and professionals dealt with the self-management of long-term conditions during general practice consultations. $17,20,24$

\section{RESULTS}

Self-management topics were introduced in $57 / 86(66 \%)$ consultations relating to longterm conditions, within which nurseinitiated self-management dialogue was more frequently observed than GP-initiated self-management dialogue. There was, however, little evidence that the structure of either routine or disease-management review appointments supported expansion of self-management dialogue. The analysis suggested that use of the QOF computer templates during consultations was both shaped by and reinforced the difficulties in supporting self-management, particularly in disease-management review appointments. These findings related to the framing of both professional-initiated and patient-initiated sequences of talk.

\section{Influencing agenda setting}

Use of the QOF computer templates was reported by professionals as influencing the delivery of care for people with long-term conditions. Although some accounts referred to the templates as providing consistency of care, there was a tendency for them to be perceived as reducing the patient's contribution to the encounter. As illustrated in nurse accounts, the need to get tasks done relating to evidence-based quality indicators took precedence and this tended to be at the expense of integrating patient-initiated dialogue into the conversation.

Nurse (N): 'Have to follow the template, don't you?'

Interviewer (I): 'Right. Okay.'

$\mathbf{N}$ : 'Everything on the template.'

I: 'Can I ask how you find the template ...?'

$\mathbf{N}$ : 'It's good, it's good because you don't miss things then, it's all there, you don't really have to think a lot for yourself. Or you can forget things, you know, if you haven't got that.'

I: 'Can I ask how ... you use the template during the consultation ...?'

$\mathbf{N}$ : 'Well you ask, you do the peak flow, you do the blood pressure, you do weight as well, all that's on it. Then you do, if there's any wheeze at night and if it's problematic, you know, if he's using his inhalers more.' (interview with nurse 09)

'I see myself in the consultation, I'm there to, I've got a job to get done, I've got, I've got my own agenda, but then the patient's got an agenda as well, so, it's driven by the things, the boxes I've got to tick for QOF and things like that, but also the patients come in with lists ... so, I'm there to facilitate information exchange, but I've got boxes of my own to tick as well. "Yes I know you've got things you want to ask, but there's things I need to do as well", and it's just a balancing act.' (interview with nurse 01)

'Yeah, you've got an agenda. They may well have an agenda. And I tend to, rightly or wrongly, get my agenda first. You know, make sure my agenda's done ... But then I do at the end sort of say... "Is that it? Do you want anything else today?" ... And sometimes that backfires on me, because then they will, you know, burst into tears and say "Oh yes, this happened to me"." 
(interview with nurse 02)

Throughout accounts, professionals referred to needing to maintain relationships with patients. As illustrated in the fragment of consultation below, attempts to achieve this while fulfilling the QOF agenda included efforts to minimise responsibility for the process. In this example, on line 14, the nurse uses the pronoun 'we' to frame the need to ask 'lots of questions.

\section{Fragment 173: PN0203}

$10 \mathrm{~N}$ : (.) now then this is just your annual check up in't it (Patient blows and uses hanky to nose)

11 Patient (P): yeah

$12 \mathrm{~N}$ : have we written to yer and invited you to come

13 P: (garble) [yeah] (garbled from patient then puts hanky away in her pocket) (overlap)

$1 \mathbf{4} \mathbf{N}$ : yeah yeah cool (..) so this just your annual review where we ask you lots of questions

15 P: alright (..) right

$16 \mathrm{~N}$ : see how you are (..) and it's following on from the funny do that you had

17 P: right yeah (..) yeah

$18 \mathrm{~N}$ : when you had a little stroke didn't you (.) you've no problems with your heart have you? (52-year-old female patient attending for a review of her stroke disease with a nursel

\section{Reinforcing a checklist approach to the encounter}

There was evidence that the computer templates reinforced a checklist approach to consultations in which professionals worked through a range of clinical parameters. However, analysis suggested that this created difficulties in discussing self-management topics. This related to the number of self-management topics raised in a consultation and the manner in which they were framed.

There was evidence that working through a list of self-management topics contributed to a sense of bombardment. For example, during an interview, which entailed generating video-stimulated accounts, a nurse described a need to address a variety of self-management topics but with awareness that this might upset the patient.

$\mathbf{N}$ : 'I mean she was feeling a bit sort of got at, the fact that l'd already had the diet and the alcohol. And then smoking was the last straw really.' (laughter)
I: 'Did it feel like that to you or ...'

$\mathbf{N}$ : 'No, no. To me it's just ... just, I ask the same questions every, you know, the same templates every single day of me working life, for somebody or other. I mean, even though I know that they smoke I've got to ask it again. I know that they eat too much; I've got to ask it again. Because that's what the screen is asking me to ask.' (interview with nurse 04)

Analysis suggested that resolving this tension was not straightforward, and as demonstrated in the next fragment of consultation (see lines 267-274), efforts tended to become focused on maintaining the relationship at the expense of more expanded self-management dialogue. Overall, as consultations proceeded through a list of template-driven parameters, dialogue concerning each subsequent selfmanagement topic tended to diminish.

\section{Fragment 162: PN0401}

(The preceding conversation dealt with the patient's weight and eating habits.)

$242 \mathrm{~N}$ : what about alcohol? (nurse looking at computer)

243 P: what about it?

$244 \mathbf{N}$ : do you drink any? (nurse turns to look at patient)

245 P: oh yes (..) far too much

$246 \mathrm{~N}$ : do you (..) how many units a week?

247 P: l've no idea I can't count so high (coughs)

$248 \mathrm{~N}$ : right seriously now (..) I'm serious now (..) how many (..) would would you drink a bottle of wine a day?

249 P: oh no not a whole bottle (..) I'd drink a couple of glasses a day

$250 \mathrm{~N}$ : every day?

251 P: no not every day but (..)

$252 \mathrm{~N}$ : (overlapping) most days? (..) and if you've had the wine is that it (..) do you have (.) drinks after your wine?

253 P: oh no

$254 \mathrm{~N}$ : no (..) so it would be your wine? (..) right okay (turns to computer)

255 P: yeah (..) I'd drink (..) I'd have more on the weekend because we tend to sit in the garden especially in summer (..) sit in the garden and have two glasses

$256 \mathrm{~N}$ : nice new garden (glances at patient) 257 (laughter)

258 P: but yeah I have a couple of glasses of wine

$259 \mathrm{~N}$ : (turns to patient) what about smoking status (...) are we still smoking (turns back to computer)

260 P: yes

$261 \mathrm{~N}$ : right (...) and have you (..) ever (..) 
thought about wanting to stop smoking?

262 P: I did once (..) you gave me them clever tablets

$\mathbf{2 6 3} \mathbf{~ N}$ : (turns to look at patient) hmm hmm (...) would you like to try again?

264 P: no (..) thank you

$265 \mathrm{~N}$ : leave it at the moment (..) that's fine (Looking back at computer screen)

266 (long pause 5 seconds)

267 P: god you've got me stopping drinking eating smoking (laughing)

268 N: NO NO NO NO NO no they are they are all major life-changing decisions

269 P: (overlapping) (cough)

$270 \mathrm{~N}$ : so l'm not saying you-

271 P: I've taken up knitting (nurse turns to patient) (..) you don't smoke as much when you knit

272 N: (laughs) I'm only trying as a professional (glances at computer screen) to advise you on that road and that's-

273 P: I know (..) I know I know

$274 \mathrm{~N}$ : (glances at computer screen) have you got a urine sample with you this morning? (48-year-old female attending for review of her hypertension with a practice nursel

Analysis also suggested that use of the QOF templates reinforced selfmanagement topics being introduced as discrete behaviours to be addressed. However, there was little evidence that such an approach led to expanded dialogue around self-management topics. Rather, analysis of consultations suggested that this had the potential to make patients answerable for their actions, resulting in a subsequent shift away from these topics of conversation. As shown in the following fragment, professionals (and patients) instead worked to repair relations and maintain the patient's sense of wellbeing.

\section{Fragment 138: PN0901}

$57 \mathrm{~N}$ : what's your diet like?

58 P: (cough)

$59 \mathrm{~N}$ : what-

60 P: I do have cheat but it does come within the erm (..) the diabetic-

$61 \mathrm{~N}$ : it's you don't go overboard with anything (looking at screen)

62 P: No

$63 \mathrm{~N}$ : you just eat sensibly

64 P: / eat sensibly yeah

$93 \mathbf{~ N}$ : do you drink much? (..) (gesture) not alcohol tea coffee water

94 P: yeah

$95 \mathrm{~N}$ : do you drink alcohol?

96 P: no / don't no
97 N: okay can I just get your blood pressure (70-year-old female attending a diabetes review appointment with a practice nurse)

\section{Disrupting patient-initiated}

\section{self-management dialogue}

The professional accounts suggested that the QOF disease-management templates were a key reason for being unable to provide ideal patient-centred notions of care.

... I try and mentally reinforce my early 1980s GP upbringing of the fundamental importance of the consultation in the practice of primary care. And I think there are strong forces mitigating against that, you know, one could start off with a sheet, or you've got a computer template, and there's all those different lines you've got to go through doctor. "And have you asked this, and have you asked that?" And what have you. And it's, it would be so easy to work your way through that like an automaton. (interview with GP11)

However, comparative analysis of interviews and recordings suggested that it was not necessarily the introduction of the computer template that created the difficulties. Rather, there was evidence to suggest that professionals turned to and used the computer templates when selfmanagement topics arose during consultations.

One illustration of this (see fragment below) is a 57-year-old man who attended a scheduled 15-minute diabetes review appointment with GP11. During this particular encounter, the patient cautiously raises concerns about his eating habits and, on line 22, tentatively suggests that this might account for deterioration in his diabetes control. It is at this point that the GP turns to the computer and then runs through various parameters, referring in the first instance to the 'normal' results (line 23). Eventually the GP mentions the urine result and the discussion shifts to the need for new medication to deal with this (lines 31-36). Through use of the computer template, a shift is observed away from the patient's presentation of the selfmanagement topic to a discussion of options around the need for medication to control the 'leaking' of 'a bit of protein' (that is, mircoalbuminurial.

\section{Fragment 169: GP1109}

11 GP: yeah (sitting forward) you're looking a lot lot better good good (overlap)

12 P: but I did book in for this because I 
thought the diabetic control would be a lot better

13 GP: uh hmm uh $\mathrm{Hmm}$

14 P: and whether it's partly the diet or not I don't know

15 GP: right

16 P: erm but it's not as good as I thought hoping it might be

17 GP: right right (glances to screen)

18 P: and as I suppose having lived with (name removed) (..) where (name removed) dive into chocolate I didn't but I suppose I got hooked on biscuits (laughs)

19 GP: right

20 P: so I do eat (..) occasionally biscuits in an evening which I would never do before 21 GP: right

22 P: so whether that's (..) affecting it I don't know (overlap)

23 GP: possibly ok (looks to screen again) You'd had these blood tests done hadn't you (..) let's have a look at some of those results then (...) and if anything your weight was down a little bit from May erm checked your blood pressure and that (..) was okay just just within the range

24 P: $h m m$

25 GP: (GP glancing between screen and patient) your HbAic that's and I think we've mentioned that before the percentage of your haemoglobin carried round in your red cells that's got some sugar attached to it (gesture) that was $8.3 \%$ so err the reading before err (..) was 6.4 so that has gone up a little bit

26 P: hmm

27 GP: it's nice to be at 7\% or below and erm (..) your cholesterol level was 3.5 which was which was in and erm okay (..) erm that's good

28: (long pause) (GP types on computer)

29 GP: we'd dipped your urine to see if there was any protein in it and the dip came back negative but then we sent it off to the lab and they've got a more sophisticated test that they can do

30 P: $\mathrm{hmm}$

31 GP: and did show that there was a little bit of err err protein in your urine what's called micro albumin err erm (..) and I think also previously that had just come (..) back a little on the high side (.) that can sometimes be an indication that erm (..) your kidneys are (..) if you like leaking a bit of protein which can be a response to the diabetes erm and there is some medication we can give you to try and prevent that something called an ACE [angiotensin-converting enzyme] inhibitor and I'm wondering whether we should erm

32 P: hmm
33 GP: have a look at that (..) I know it's yet another tablet to take that's that's the thing 34 P: well well I was hoping two or three I could perhaps stop taking

35 GP: right right (looks to computer) shall we have a look at your medication

36 P: yeah (..) I need some more anyway (.......). (57-year-old male attending a 15minute diabetes review appointment with a GP)

\section{DISCUSSION}

\section{Summary}

It is known from previous research that the use of decision aids and management tools produces tensions in the role of the GP acting as authoritative clinician versus a more neutral decision-support tool implementer. ${ }^{30}$ The analysis in this study suggests that use of diseasemanagement' templates tended to be associated with a disruption in patientinitiated self-management dialogue, with the risk of marginalising patient agenda setting. Examples were observed where, through use of the computer, professionals shifted the topic of conversation away from self-management issues to medical matters. The analysis does not imply that management through medication is irrelevant, but rather it is hypothesised that the conversation does not broaden to consider lifestyles issues raised and that the computer templates provided a mechanism for limiting consideration of these issues.

The templates were also seen to reinforce a checklist approach to the consultation in which professional-initiated selfmanagement dialogue was framed as discrete behaviours. This approach tended to result in efforts to maintain relations but at the expense of expanded selfmanagement dialogue. Overall, it appeared that use of the computer templates reinforced the difficulties in supporting selfmanagement.

\section{Strengths and limitations}

The study was hypothesis-generating and entailed comparative analysis of both observational and interview data to gain greater understanding of self-management support. In addition to analysis of multiple types of data, maximum variation sampling of GPs was carried out to understand typical practice. It is acknowledged that recruitment of additional participants may have enhanced the trustworthiness of the findings and may have identified alternative approaches to using clinical information systems. ${ }^{31}$ It is also recognised that 
pragmatic recruitment of nurses from practices in which GPs had already agreed to participate may have limited the range of nurse characteristics sampled. Furthermore, as opposed to more general reports of self-management support in general practice, generating videostimulated accounts during the patient interviews may have enabled greater understanding of the relevance of the computer templates in consultations. 17,18,27 Comparisons with pre-QOF consultations would have assisted understanding. It is also recognised that the study was conducted in the UK context, where the use of clinical information systems is directly related to practice remuneration. ${ }^{4}$

\section{Comparison with existing literature}

There is evidence that the QOF has improved the quality of clinical aspects of care without detriment to interpersonal aspects of care during consultations, 12,13 which would clash with the current findings. However, existing instruments measuring interpersonal care lthe General Practice Assessment Questionnaire [GPAQ] and GP Patient Survey [GPPS]) do not adequately measure self-management support. ${ }^{32}$

Previous professional accounts have attributed difficulties in providing personcentred care to the QOF. ${ }^{33-35}$ However, there is evidence, both in the UK and internationally, to indicate that a biopsychosocial approach that includes discussion around self-management of long-term conditions may be more 'rhetoric' than 'reality. ${ }^{36-39}$ Through comparative analysis of both observational and interview data, the present findings suggest it is problematic to treat the QOF templates merely as external determinants of behaviour. Rather, it is hypothesised that the use of computer templates is shaped by other motivators of professional behaviour. Although reportedly valued, professionals may lack the necessary skills to support self-management in primary care. ${ }^{16,40}$ From this perspective, use of the QOF templates may be viewed as a communication strategy' to manage these difficulties when they arise during consultations. ${ }^{41}$ If the QOF templates were not present, it may be that professionals would find other mechanisms, such as note taking, to achieve the same goal of shifting conversation away from topics they find uncomfortable.
The present research supports existing literature, which suggests that it is the threat to the maintenance of the patient-professional relationship that is an important motivator of behaviour in consultations with people with long-term conditions. ${ }^{17,28}$ The study suggests that structures such as current clinical information systems reinforce difficulties: they bring self-management topics into view, but their design does not necessarily address the tensions underpinning selfmanagement support. 16,17,42 The present findings highlight the importance of considering the interactions between the multiple components of care in the Chronic Care Model. ${ }^{1}$

\section{Implications for practice and research}

Current policy has intensified rather than reduced the tensions underpinning selfmanagement support. Through funding arrangements, general practices are responsible for ensuring that health-related behaviours are addressed. ${ }^{4}$ At the same time, through patient experience surveys, practices and practitioners are also funded for demonstrating patient satisfaction with their care.4,32 The present analysis suggests that professionals attempt to resolve this tension through a variety of manoeuvres, which result in maintenance of the patient-professional relationship but at the expense of more expanded selfmanagement dialogue. ${ }^{17}$ As previous studies have shown, professionals feel unable to 'challenge' patients, and work to maintain relationships by colluding with illness behaviour that sustains incapacity. ${ }^{43}$ The analysis of this study suggests that structures, models, and policies need to acknowledge the distinction between interpersonal care and self-management support.

The authors published work has identified a tension between addressing self-management topics while maintaining patient-professional relations. ${ }^{17}$ The current analysis suggests how this tension is both reinforced by the use of QOF computer templates, and shapes the use of templates within consultations. To improve management of long-term conditions in primary care, the design and implementation of clinical information systems need to address the tensions underpinning self-management support.

time and contribution.

\section{Discuss this article}

Contribute and read comments about this article on the Discussion Forum: 


\section{REFERENCES}

1. Wagner EH, Austin BT, Davis C, et al. Improving chronic illness care: translating evidence into action. Health Aff 2001; 20(6): 64-78.

2. Department of Health. Supporting people with long term conditions: an NHS and social care model to support local innovation and integration. London: Department of Health, 2005

3. Wagner E. Chronic disease management: what will it take to improve care for chronic illness? Eff Clin Pract 1998; 1(1): 2-4

4. Department of Health. Investing in general practice: the new General Medical Services Contract. London: Department of Health, 2003.

5. Skills for Care and Skills for Health. Common core principles to support self care: a guide to support implementation. London: Department of Health, 2008.

6. Department of Health. The NHS improvement plan: putting people at the heart of public services. London: Department of Health, 2004.

7. Department of Health. Self care - a real choice: self care support - a practical option. London: Department of Health, 2005.

8. Department of Health. Public attitudes to self care baseline survey. London: Department of Health, 2005.

9. Bodenheimer T, Lorig K, Holman H, Grumbach K. Patient self-management of chronic disease in primary care. JAMA 2002; 288(19): 2469-2475.

10. Singh D, Ham C. Improving care for people with long-term conditions: a review of UK and international frameworks. Birmingham: HSMC, 2006.

11. Tsai A, Morton S, Mangione C, Keeler E. A meta-analysis of interventions to improve care for chronic illnesses. Am J Manag Care 2005; 11(8): 478-488.

12. Campbell SM, Roland MO, Buetow SA. Defining quality of care. Soc Sci Med 2000; 51(11): 1611-1625

13. Campbell SM, Reeves D, Kontopantelis E, et al. Effects of pay for performance on the quality of primary care in England. N Engl J Med 2009; 361(4): 368-378.

14. Gillam S. Should the Quality and Outcomes Framework be abolished? Yes. BMJ 2010; 340: c2710.

15. Maisey S, Steel N, Marsh R, et al. Effects of payment for performance in primary care: qualitative interview study. J Health Serv Res Policy 2008; 13(3): 133-139.

16. Blakeman T, Macdonald W, Bower P, et al. A qualitative study of GPs' attitudes to self-management of chronic disease. Br J Gen Pract 2006; 56(527): 407-414.

17. Blakeman T, Bower P, Reeves D, Chew-Graham C. Bringing selfmanagement into clinical view: a qualitative study of long-term condition management in primary care consultations. Chronic /lln 2010; 6(2): 136-150.

18. Collins S, Britten N, Ruusuvuori J, Thompson A. Patient participation in health care consultations: qualitative perspectives. Maidenhead: Open University Press, 2007.

19. Crotty M. The foundations of social research: meaning and perspective in social research. London: Sage, 1998.

20. Charmaz K. Constructing grounded theory: a practical guide through qualitative analysis. London: Sage Publications Ltd, 2006.

21. Silverman D. Analyzing talk and text. In: Denzin N, Lincoln Y (eds). Collecting and interpreting qualitative materials. 2nd edn. Thousand Oaks: Sage Publications, 2003: 340-362.

22. Chew-Graham CA, May CR, Perry MS. Qualitative research and the problem of judgement: lessons from interviewing fellow professionals. Fam Pract 2002; 19(3): 285-289.
23. Charmaz K. Discovering chronic illness: using grounded theory. Soc Sci Med 1990; 30(11): 1161-1172.

24. Rapley T. Doing conversation, discourse and document analysis. London: Sage Publications Ltd, 2007.

25. Gubrium J, Holstein J. Analyzing interpretive practice. In: Denzin N, Lincoln Y (eds). Strategies of qualitative inquiry. 2nd edn. Thousand Oaks: Sage Publications, 2003: 214-248.

26. Potter J. Discourse analysis as a way of analysing naturally occurring talk. In: Silverman D (ed). Qualitative research: theory, method and practice. 2nd edn. London: Sage Publications, 2008: 200-221.

27. Coleman T, Murphy E. Combining qualitative interviews with video-recorded consultations: gaining insight into GPs' decision-making. Fam Pract 1999; 16(2): 173-178.

28. Heritage J, Maynard D. Communication in medical care: interaction between primary care physicians and patients. Cambridge: Cambridge University Press, 2006.

29. Poland BD. Transcription quality as an aspect of rigor in qualitative research. Qual Inq 1995; 1(3): 290-310.

30. Rapley T, May C, Heaven B, et al. Doctor-patient interaction in a randomised controlled trial of decision-support tools. Soc Sci Med 2006; 62(9): 2267-2278.

31. Lincoln Y, Guba EG. Naturalistic inquiry. London: Sage, 1985.

32. Campbell J, Smith P, Nissen S, et al. The GP Patient Survey for use in primary care in the National Health Service in the UK - development and psychometric characteristics. BMC Fam Pract 2009; 10: 57.

33. Campbell S, McDonald R, Lester $\mathrm{H}$. The experience of pay for performance in english family practice: a qualitative study. Ann Fam Med 2008; 6(3): 228-234.

34. Hasegawa H, Reilly D, Mercer SW, Bikker AP. Holism in primary care: the views of Scotland's general practitioners. Prim Health Care Res Dev 2005: 6(4): 320-328.

35. McDonald R, Harrison S, Checkland K, et al. Impact of financial incentives on clinical autonomy and internal motivation in primary care: ethnographic study. BMJ 2007; 334(7608): 1357.

36. Dowrick C, May C, Richardson M, Bundred P. The biopsychosocial model of general practice. Br J Gen Pract 1996; 46(403): 105-107.

37. Glasgow RE, Whitesides H, Nelson CC, King DK. Use of the Patient Assessment of Chronic Illness Care (PACIC) with diabetic patients: relationship to patient characteristics, receipt of care, and self-management Diabetes Care 2005; 28(11): 2655-2661

38. Shortus T, McKenzie S, Kemp L, et al. Multidisciplinary care plans for diabetes: how are they used? Med J Aust 2007; 187(2): 78-81.

39. Campion P, Foulkes J, Neighbour R, Tate P. Patient centredness in the MRCGP video examination: analysis of large cohort. BMJ 2002; 325(7366): 691-692.

40. Macdonald W, Rogers A, Blakeman T, Bower P. Practice nurses and the facilitation of self-management in primary care. J Adv Nurs 2008; 62(2): 191-199.

41. Barry CA, Stevenson FA, Britten N, et al. Giving voice to the lifeworld. More humane, more effective medical care? A qualitative study of doctor-patient communication in general practice. Soc Sci Med 2001; 53(4): 487-505.

42. Young $G$, White B, Burgess J, et al. Conceptual issues in the design and implementation of pay-for-quality programs. Am J Med Qual 2005; 20(3): 144-150.

43. Chew-Graham C, May C, Roland M. The harmful consequences of elevating the doctor-patient relationship to be a primary goal of the general practice consultation. Fam Pract 2004; 21(3): 229-231. 